\title{
BENEFITS AND THREATS OF NEUROMARKETING: THEORETICAL BACKGROUND AND PRACTICAL USE
}

\author{
Marcin ANTONIAK \\ Poznań University of Economics and Business, Department of Commerce and Marketing; \\ marcin.antoniak@phd.ue.poznan.pl, ORCID: 0000-0003-0920-9540
}

\begin{abstract}
Purpose: the present paper aims to explore the origins of neuromarketing, its current position, technologies and major limitations, as well as to discuss its possible future development.

Design/methodology/approach: this is a theoretical article. For its purposes an in-depth literature review has been conducted. Additionally, in order to shed light on challenges faced by researchers using neuromarketing tools, the currently available knowledge has been synthesized.

Findings: the study has shown that neuromarketing technologies provide invaluable information on the subconscious mental processes influencing the customer's behaviour. However, despite their considerable scientific potential, they pose potential threats regarding their unauthorised use. Hence, the research emphasises the need to maintain particularly high standards and to protect people against inappropriate and unethical use of neuromarketing strategies .

Originality/value: the paper can be used by theoreticians and practitioners of neuroeconomics who want to deepen their knowledge of research and tools used in neuromarketing. It presents the most frequently used technologies as well as the opportunities and threats related to their use in an in-depth and innovative way.
\end{abstract}

Keywords: neuromarketing, neuroeconomics, neuroscience, marketing, marketing research.

Category of the paper: General review.

\section{Introduction}

The term neuromarketing has frequently been used in the media in recent years. Nonetheless, providing its precise definition poses a considerable challenge owing to a significant variety of approaches adopted in literature. Neuromarketing can be described as a tool for customer relationship management (CRM), built on the basis of understanding the fundamental functional mechanisms of the nervous system (Plakhin, Semenets, Ogorodnikova, \& Khudanina, 2018). It is considered to be an expansion of neuroeconomics (Pop, Dabija, 
\& Iorga, 2014) and a combination of marketing, neuroscientific methods and consumer psychology. This tool seeks to apply principles, methodologies and research findings of neuroscience with a view to advancing the understanding of key human patterns of behaviour (Hubert \& Kenning, 2008). Furthermore, while Ariely and Berns define neuromarketing as the application of neuroimaging methods to product marketing (Ariely \& Berns, 2010), Macdonald considers it as a tool utilising brain imaging to measure the consumer's desire for a product (Macdonald, 2011). According to other explanations, neuromarketing constitutes a discipline employing advanced technology in order to devise more effective ways of satisfying the consumer (Ouazzani Touhami et al., 2011) or a commercial marketing communication field applying neuropsychology to market research (Lee, Broderick, \& Chamberlain, 2007). Furthermore, neuromarketing may also refer to the use of modern brain science to measure the impact of marketing and advertising on the consumer (Genco, Pohlmann, \& Steidl, 2013). Finally, Collins dictionary defines neuromarketing as a process of researching consumers' brain patterns (Dictionary, 2019).

The origins of neuroscience date back to the technical boom and the appearance of technologies scanning and imaging the human body. However, what enabled the development of such new sub-fields as neuroeconomics, neuromarketing and consumer neuroscience was the advancements in the use and implementation of imaging technologies (ŚwierczyńskaKaczor, 2015). Although the term was introduced by Ale Smidts in 2002, it was Professor Martin Lindstrom who was the driving force of the discipline (Šola, 2013). The beginnings of neuroscience can also be associated with 2004, when a number of neuroscience articles were published following the Invitational Choice Symposium (Shiv, Alba, Bettman, Mellers, \& Mcgraw, 2005).

Substantial progress has been made since that time, with the result that the application of neuromarketing has fundamentally changed the way marketers design, promote, value and pack products (Fugate, 2007). Marketers presently aspire to increase their understanding of customers with a view to comprehending the ways individuals invest resources available to them into merchandise (Šola, 2013). They also intend to examine the customer's reactions to products, brands and various marketing strategies (Mucha, 2005). As far as consumption is concerned, the supplier is expected to understand, predict and satisfy the consumer's needs and desires (Schiffman, Kanuk, \& Wisenblit, 2010).

All the aforementioned factors have indubitably made their contribution to the growing importance of understanding the functioning of the brain and the assessment of available options in the decision-making process (Levy \& Glimcher, 2012). Since traditional tools measuring the effectiveness of marketing strategies no longer proved sufficient, there has appeared an immediate need for neuromarketing, a combination of neuroscience, clinical psychology and economy. Hence, a new revolution in marketing is liable to accompany the development of neuromarketing technologies (Perrachione \& Perrachione, 2008). 
The paper is divided into five sections. The first discusses neuromarketing history and development. The second section outlines the most important neuromarketing technologies, focusing on their advantages and disadvantages. The subsequent section describes the anatomy of the human brain, memory and emotions, with a view to enhancing the understanding of neuromarketing functioning, along with its ways of affecting people. The fourth part evaluates the challenges any potential malicious use of neuroscience poses to the customer's wellbeing and offers a number of protective measures to be undertaken. Finally, the closing section exemplifies the practical use of neuromarketing strategies.

\section{Historical overview}

The term 'neuromarketing' was first used in 2002 in an article published by BrightHouse, a marketing company based in Atlanta, Georgia (Ait Hammou, Galib, \& Melloul, 2013). Subsequently, it was added to The Collins Dictionary by Harper Collins in 2005 (Morin, 2011). This term was initially used by BrigtHouse and SalesBrain (Morin, 2011).

The history of neuromarketing started in 1878, when Richard Canton discovered electrical signals in animals' brains. Among the first techniques used in present-day neuromarketing research was electroencephalogram (EEG), introduced by Hans Berger in 1924 (Gloor, 1969). Almost half a century later magnetoencephalography appeared, discovered by David Cohen in 1968 (Cohen, 1968). Positron emission topography (PET) then followed, introduced by Ter-Pogossian and his colleagues in 1975 (Ter-Pogossian, Phelps, Hoffman, \& Mullani, 1975). The next decade witnessed the discovery of transcranial magnetic stimulation (TMS), made by Antony Barker's team (Barker, Jalinous, \& Freeston, 1985). Functional magnetic resonance imaging (fMRI) followed soon after, launched by Ogawa and his colleagues in 1990 after the development of structural magnetic resonance imaging (Ogawa, Lee, Kay, \& Tank, 1990). The final major stage in the development of neuroimaging methods was reached thanks to functional near-infrared spectroscopy (fNIRS), first used in 1993 (Boas, Elwell, Ferrari, \& Taga, 2014).

The 1990s is at times referred to as the brain decade, owing to a dramatic increase in the use of EEG and other brain imagining techniques (Illes, 2003). However, it was Martin Lindstrom, an Oxford University professor, who can be identified as the driving force of neuromarketing. Nowadays, neuromarketing appears to begin where traditional marketing research of consumer behaviour ends (Šola, 2013). It begins anew every time we go shopping and decide which brands to buy. 


\section{Neuromarketing technologies}

EEG (electroencephalogram) is a non-invasive method of recording data through analysing brain electrical activity. EEG measures changes in electrical neural activity in the cortex via a series of electrodes attached to the scalp (Ariely \& Berns, 2010; Ciorcari, 2012). The technology was discovered by Richard Carton in 1875. Among the fathers of this new technology was Polish physiologist Adolf Beck, who published his thesis on spontaneous electrical activity in the brains of rabbits and dogs (Coenen, Fine, \& Zayachkivska, 2014). EEG has both its advantages and disadvantages as compared with other neuroimaging techniques. Amongst the main aspects distinguishing EEG are its non-invasiveness and relatively low price. Additionally, it measures brain electrical activity, while some other methods record blood flow changes or metabolic activity. The major limitation of EEG lies in its inability to accurately identify the location of a specific brain activity (Ahlert, Kenning, \& Plassmann, 2006). EEG is frequently combined with other methods, such as fMRI or NIRS. It can also be used at the same time as MEG (Oğuz Tanzer, 2006) or together with eye tracking (Khushaba, Kodagoda, Takruri, \& Dissanayake, 2012).

fMRI (functional magnetic resonance imagining) is a specialised type of magnetic resonance imaging, measuring the increase of cranial blood flow and the oxygenation of active brain regions (Pradeep, 2010). The first MRI-based human body scan was performed by Professor Raymond Damadian in 1977 (Mattson \& Simon, 1996). The primary form of fMRI uses the blood-oxygen-level dependent contrast (BOLD) (Huettel, Song, \& McCarthy, 2008). Nowadays, fMRI provides the opportunity to study neural activity in the human brain in almost real time (Ashby, 2011). The fMRI uses a strong, albeit harmless, magnetic field and radio waves. It can also graphically display the pattern and strength of specific brain activation (Ienca $\&$ Andorno, 2017), relying on a higher blood flow in activated areas (Logothetis, Pauls, Augath, Trinath, \& Oeltermann, 2001). The main disadvantage of this technology consists in the negligible impact of brain activation on the detectable blood oxygenated levels, rendering the recording of certain cognitive processes impossible (Sanei \& Chambers, 2007).

MEG (magnetoencephalography) is a neuroimaging technique, developed by David Cohen in 1968 (Boto et al., 2018), used for mapping brain activity. It is based on measuring changes in magnetic fields occurring as electrical brain activity fluctuates (Ariely \& Berns, 2010; Kenning \& Plassmann, 2005). The technique uses particularly sensitive magnetometers, such as SQUIDs (superconducting quantum interference devices) or SERF (spin exchange relaxation-free) (Boto et al., 2018).

PET (positron-emission tomography) was originally the most functional imaging technique of nuclear medicine, which recorded radiation emitted during the annihilation of positrons included in radioactive substances containing short half-life isotopes. PET detects gamma rays and measures gamma radiation produced during the decay of radioactive molecules 
administered prior to the scan (Plassmann, Ambler, Braeutigam, \& Kenning, 2007). However, PET technology is enormously expensive (Boto et al., 2018) in comparison to other brain mapping techniques, thus it is rather infrequently used in consumer neuroscience research.

BCI (brain-computer interface) is a direct communication pathway between the brain and an external device. BCI allows for bidirectional information flow and can be used for mapping human cognitive or sensory-motor functions (Krucoff, Rahimpour, Slutzky, Edgerton, \& Turner, 2016). The origins of this technology can be traced back to 1969, when E.E. Fetz and his colleagues from Washington University started to analyse the behaviour of monkeys (Fetz, 1969). Until recently, the interface was used by Professor Stephen Hawking for the purpose of delivering university lectures.

tDCS (transcranial direct current stimulation) is a form of neuromodulation which uses a constant, low direct current delivered via electrodes on the head. The tool was originally invented over one hundred years ago to help people with brain damage or depression (Brunoni et al., 2016; Mutz et al., 2019). Giovanni Aldini then used the technique to improve the mood of melancholy patients (Parent, 2004). Research has provided evidence that the method can also be used for cognitive improvements (Dedoncker, Brunoni, Baeken, \& Vanderhasselt, 2016; Hill, Fitzgerald, \& Hoy, 2016; Katsoulaki, Kastrinis, \& Tsekoura, 2017).

TMS (transcranial magnetic stimulation) is a non-invasive form of brain stimulation through electromagnetic induction. Stable TMS devices were introduced in 1985 as diagnostic and research tools (Horvath, Perez, Forrow, Fregni, \& Pascual-Leone, 2011). The technology uses a stimulator connected to the scalp, which generates electrical current within a special coil inducing a magnetic field. The main advantage of TMS is its ability to validate which brain regions play a key role in particular cognitive functions. Furthermore, it can identify whether a brain region determines a particular behaviour or whether that behaviour is the result of interconnections between brain regions (Banich \& Compton, 2010). The limitations of TMS consist in that it only stimulates brain regions close to the scalp, as well as its inability to precisely stimulate small and isolated brain structures (Harris, Ciorciari, \& Gountas, 2018).

DBS (deep brain stimulation) is a neurosurgical procedure whereby a medical device is implanted in the brain. Using an electrode, the device transmits impulses in the selected brain area, resulting in direct changes in brain activity. The technology is commonly used for medical purposes rather than in neuromarketing. However, if hacked, it could be used in a malicious way.

Eye tracking is a technique aimed at measuring eye behaviour (Isabella, Mazzon, \& Dimoka, 2015) by tracking the focus of sight, eye movements and the size of the pupil. The history of eye tracking observations dates back to the 1800 s. The first non-intrusive eye tracker was built by Thomas Buswell. Eye tracking is an effective technique for measuring eye fixations, saccades, smooth pursuits and nystagmoids (Andreassi, 2007). This technology also enables the measurement of changes in the size of the pupil (pupillometry), serving as a reliable 
indicator of emotional arousal (Bradley, Miccoli, Escrig, \& Lang, 2008). Due to its relatively low price, eye tracking has become an essential neuromarketing tool.

Face Reading (facial electromyography - fEMG) is a technology whose origins can be traced back to the 1970s, when Paul Ekman and his colleagues discovered six primary emotional expressions: anger, disgust, fear, happiness, sadness and surprise (Ekman \& Friesen, 1971). From the very beginning, face reading technologies have been based on direct measurements performed via sensors placed on the face. Today, the technique allows for automated observations made with the use of a camera and professional software. The efficiency of this technology results from its ability to gauge approach and withdrawal responses (Bolls, Lang, \& Potter, 1995). Hence, face reading has become an easy and relatively inexpensive tool used in neuromarketing.

EKG, also known as ECG (Electrocardiogram), is a standard tool for measuring heart rate. This analysing technique is based on the fact that heart rate slows down when one is calm and relaxed and speeds up when one becomes exited, fascinated or focused (Bridger, 2015). This heart rate analysing technique is recommended for use with other neuromarketing tools, such as EDA, eye tracking, EEG or fEMG (Harris et al., 2018).

EDA (electrodermal activity) is a measure of skin conductance, also known as galvanic skin response (GSR) or electrodermal response (EDR). As skin conductance may provide information about the emotional state (Carlson, 2012), EDA measures reflect both arousal and pleasure (Wang \& Minor, 2008). It is highly responsive to psychologically relevant stimuli (Lajante \& Ladhari, 2019) and is associated with psychological arousal (Kim \& Fesenmaier, 2015). The beginnings of this technique can be traced back to 1849, when Reymond Dubois discovered that human skin is electrically active. EDA is relatively inexpensive and easy to use. It is regarded as a highly popular method for investigating human psychophysiological phenomena (Boucsein, 2012) and is often accompanied by other measures, such as EEG or fEMG (Li, Scott, \& Walters, 2014).

\section{The human brain, memory and emotions}

The human brain has been a source of fascination to researches for decades. It forms part of the nervous system, the major controlling, regulatory and communicating system of the body (Zurawicki, 2010). It is the brain which plays a decisive role in the shaping of our character, for it records our history, experiences, memory and emotions. Thanks to it, we are capable of making decisions, not the least of which relate to shopping preferences. The volume of the brain is $800-2,000 \mathrm{ml}$, which corresponds to a weight of $1.2-1.4 \mathrm{~kg}$, and constitutes only about $2 \%$ of the total weight of the human body. Nonetheless, it consumes as much as $20 \%$ of the energy supplied to the whole body. The brain may be divided according to clinical and topographical 
factors. According to the topographical map, it is divided into the forebrain, the midbrain, and the hindbrain (Zurawicki, 2010). From the clinical perspective, it consists of the cerebrum, the cerebellum and the brainstem. The two sides of the brain are joined at the bottom by the corpus callosum. The surface of the cerebrum contains neurons and glia, together forming the cerebral cortex and grey matter. Deeper parts of the cerebrum are mainly composed of white matter (Zurawicki, 2010).

The cerebral cortex is responsible for the most demanding intellectual functions, namely thinking, planning and problem solving. From the neurological viewpoint, what exerts a strong influence on consumer behaviour is the deep and evolutionarily old brain structures: the thalamus, the hypothalamus, the amygdala and the hippocampus, which are also referred to as the limbic system. They are involved in learning, formatting and processing emotions and are responsible for memory (Zurawicki, 2010).

The cerebellum is located under the cerebrum, at the back of the brain (Zurawicki, 2010). It controls muscle movements, posture and balance. Additionally, it fine tunes motor activity and movement. It plays a crucial role in the ability to perform rapid and repetitive actions.

The brainstem is a brain extension connecting the cerebrum and the cerebellum to the spinal cord (Zurawicki, 2010). It consists of the midbrain, the pons and medulla oblongata and controls a number of automatic functions. In some countries, human death is considered to occur when the brainstem loses its functions, which is known as brainstem death.

Memory is the ability to record and recall sensory impressions, associations and information. In other words, it can be described as the conscious and intentional recollection of factual information, previous experiences and concepts (Ullman, 2004). According to the time criterion, memory can be divided into long-term, short-term and ultra-short-term (sensory). Long-term memory (LTM) performs the function of permanent storage. It is divided into declarative and non-declarative memory. Short-time memory (STM) involves temporary functions and changes in synapses. It also has the shortest duration and the largest capacity, as it can store approximately $99 \%$ of all incoming information. It is responsible for processing and filtering data received by the brain from incoming stimuli.

Time fails to form the sole criterion for the division of memory, for its types may also be differentiated according to their functions, the ways of storing and processing data, as well as the influence they have on the human life. For instance, one can distinguish declarative and non-declarative (implicit) memory, both of which form part of LTM. The latter type, acquired and used unconsciously, is able to affect thought and behaviour (Schacter, 1987).

Declarative memory can be further subdivided into autobiographical and semantic. While the former is related to one's own past, the latter is associated with facts (objects and events) and the meanings of words. Semantic memory consists of encyclopaedic and descriptive knowledge, uninfluenced by personal experiences (Zurawicki, 2010). General laws, formulas and grammar rules are also stored there. 
Episodic (event) memory, a type of declarative memory, stores episodes from an individual's life, as well as information about the relationship between events. Hence, it is context-specific and vivid. According to Zurawicki (2010), the recall of significant past events sets them not only within the context of time and space, but also emotions.

Working memory constitutes both a buffer for passive storage of information for a short period of time and a kind of work space where conscious processing of information occurs.

Fresh memory lasts up to several minutes following the acquisition of information. During this time, electrical impulses circulate in multi-neuronal chains of feedback stimulation, including hills and the cerebral cortex. Although in psychology literature this is a synonym for short-term memory, these two types fail to be equivalent.

Yet another type of memory deserving of attention is procedural (movement) memory. It can be classified as a kind of long-term memory associated with ways of performing activities.

Emotions are a crucial aspect of memory, enabling the brain to combine memories with appropriate emotional responses. They can be described as positive or negative experiences associated with particular patterns of psychological activity. Experiencing an emotion in a conscious way involves its formation from a past or hypothetical experience linked back to a content state of pleasure or displeasure (Wilson \& Dunn, 2004) Emotions are liable to have a deep impact on an individual. They involve physiological components, cultural or emotional labels (e.g. anger, surprise), expressive body actions and the appraisal of situations and contexts (Thoits, 1989)). At times, one may experience an emotional flow towards some people, things or events without realising or remembering the source of such an emotional state. The processing and conscious experiencing of emotional information may occur in different parts of the brain (Winkielman, Knutson, Paulus, \& Trujillo, 2007). As it leads to a variety of physiological, behavioural and cognitive changes, intense emotional arousal may influence individuals to such an extent that they perform actions they would do in different circumstances. Furthermore, emotions frequently play a key role in the decision-making process, for example during shopping.

\section{Privacy protection}

Despite the fact that rapid neuromarketing advancements have offered new possibilities, they have equally raised controversial ethical concerns. Some critics argue that neuromarketing may be used to deprive customers of their freedom by collecting, sharing and manipulating information received via scanning and testing human brain activity. Thus, neuromarketing raises questions concerning human rights, namely the right to cognitive liberty, mental privacy, mental integrity and psychological continuity (Ienca \& Andorno, 2017). 
The right to cognitive liberty, or the right to mental self-determination, involves the freedom to control one's own mental processes, cognition and consciousness. It involves the freedom from interference and the right to self-determination. The restriction of the former may take the form of influencing cognition and altering or monitoring mental processes without one's knowledge. Such a situation may be exemplified by actions undertaken by the US government prior to the 1970s requiring homosexuals to be mandatorily treated psychiatrically. What also constitutes a limitation of the freedom from interference was the CIA Project MKUltra, as well as the non-consensual administration of psychoactive drugs to some US citizens (Boire, 1999). Quite the contrary, the right to self-determination consists in the freedom to alter or enhance one's own consciousness (Boire, 1999).

The right to mental privacy forms part of the broadly understood human privacy. However, the infosphere is nowadays more intrusive than has ever been in history (Ienca \& Andorno, 2017). A 2015 short article published by Nature magazine states that the times of privacy are gone (Enserink \& Chin, 2015). This viewpoint is shared by Moore (Moore, 2010). Recently, the media have been exposing activities concerning the use of computers and smartphones undertaken by Facebook and Google in order to monitor their customers' conversations. Therefore, also taking into account the possibilities of monitoring facial expressions via cameras installed in computers or mobile phones, one can indubitably state that a tool for monitoring mental privacy has just been created and used. Furthermore, the Facebook team claimed in 2017 that they were working on a brain-computer speech-to-text interface to translate thoughts directly from brain signals. Human privacy, including brain activity privacy, is protected by such documents as the United Nations Universal Declaration of Human Rights issued by the European Council, the European Convention on Human Rights, the European Union Data Protection Derivative, as well as local laws.

Mental integrity is the mastery of one's mental states and brain data, which nobody is allowed to read, spread or alter without permission (Lavazza, 2018). Mental integrity is also perceived as one of the most basic human rights (Lavazza, 2018). Thus, the importance of the freedom to control one's own consciousness and electrochemical thought processes is cardinal (Sententia, 2006). The right to mental integrity is protected by the third article of the European Union's Charter of Fundamental Rights and the European Union Fundamental Rights Agency. However, devices that might influence the human brain and mental integrity already exist, and their development is rapid. Such a device as a BCI (brain-computer interface) is able to interfere with brain signals from a certain distance. Yet another device, known as DBS (deep-brain stimulation), aimed to provide medical treatment, can also be used to produce signals changing one's mental state of mind, causing apathy, compulsive behaviour or hallucinations (Mackenzie, 2011). Additionally, in 2019, Russia claimed to have created the 5P-42 Filin military system, which interferes with the human brain through the use of lasers. 
According to Britannica, "psychological continuity consists of the holding of a number of psychological relations between person-stages, e.g. relations that hold when beliefs and desires produce, through reasoning, new beliefs, desires, intentions or decisions, as well as the holding of relations that are involved in the retention over time of personality and character traits"(Britannica, 2019). In other words, it relates to personal identity, namely the continuity of personal experiences, thoughts, choices and preferences, which should be protected. However, privacy understood as such may be threatened if neurotechnological devices are used in a malicious way. For instance, tDCS (Transcranial Direct Current Stimulation) can continuously stimulate the brain and, by changing the polarisation of neurons, adversely affect brain functions. Modifications in the functioning of the brain may also arise from the application of TMS (Transcranial Magnetic Stimulation) and DBS (Deep Brain Stimulation). Such changes may result in the alteration of personal identity (Decker \& Fleischer, 2008), exhibited by an increase in impulsivity, aggressiveness or sexual behaviour (Frank, Samanta, Moustafa, \& Sherman, 2007; Houeto et al., 2002).

Despite widespread fears regarding neuromarketing, the question remains as to which of them are realistic, as the topic has yet to be further researched. Nonetheless, what is required is caution, rapid reaction to any potential threats, objectivism, as well as common sense.

\section{Neuromarketing limitations and practical use}

Neuroeconomics is considered to use neuroscience to explain the mechanisms of decision making, including those relating to the purchasing process. Therefore, many scientists and researchers are eager to understand the psychological mechanisms responsible for the processing of decision-making (Camerer, Loewenstein, \& Prelec, 2004). Neuromarketing also influences various aspects of marketing, such as introducing new products, designing packaging and distributing products (Reynolds, 2006). Nevertheless, it also has a number of limitations. An important limitation concerns the cost of purchasing and maintaining the necessary equipment. Another limitation is related to the ecological validity of isolated research studies requiring participants to lie flat in a rather uncomfortable position, frequently exposed to the noise of imaging machinery (Spence \& Piqueras-Fiszman, 2014). Finally, under no circumstances should the moral side of research be underestimated.

The constraints and difficulties of neuromarketing can be exemplified by the case popularly known as 'The Pepsi Paradox' (Lone, 2009; Morin, 2011; Van Doorn \& Miloyan, 2018). Although Coca-Cola was the US market leader in the 1980s, its shares were already beginning to drop in favour of Pepsi at that time. Accordingly, Coca-Cola decided to conduct its own internal taste tests, the results of which indicated that it was not the original taste that customers preferred, but a new, sweeter one. The clarity of the test results led to the launch of a new 
product in 1985. However, following its introduction, Coca-Cola received over 400,000 letters of complaint, and its sales continued to drop even further. In spite of the preference for the sweeter taste, customers were emotionally bound with the original flavour and refused to accept the newly introduced drink. A few years afterwards, the modified version of Coca-Cola was withdrawn from the market. Hence, the research results showed that, in the purchasing process, greater significance is attached to emotions and positive memories than to the purely technical aspects of a product. However, further research is yet to be conducted in order to extend the knowledge about emotions, memories and other dimensions of the purchasing process.

\section{Conclusions}

Over the past decades, consumer neuroscience has made substantial progress in generating insights related to marketing and consumer behaviour. Additionally, the amount and variety of neurotechnology applications have been on a sharp increase. Since neuromarketing provides new approaches to understanding customer behaviour, it addresses such issues as the consumer's reactions to products, advertisements and special offers, as well as ways of purchasing products and services. This knowledge enables marketers to plan marketing activities and launch new products in more efficient ways.

Neuromarketing is a continuously developing field, whose mysteries are still being uncovered. There is no denying the fact that more time is needed to explore all of its assets. This growing trend constituted the primary motivation for writing the present article. Therefore, the paper has discussed the history of neuromarketing, the most frequently used technologies, as well as the role of the brain, memories and emotions in neuromarketing. What has also received attention has been data privacy and ethical issues related to neuromarketing research. Finally, it has been explained how neuromarketing functions in practice. However, the full understanding of human behaviour in response to marketing techniques still requires further research. Thus, the author aims to pursue the research of customer behaviour by determining the ways in which conscious intentions influence attitudes and final decisions. To this end, the author plans to juxtapose the results of neuromarketing studies with qualitative and quantitative data.

Despite its considerable scientific potential, neuroscience creates a temptation for use in an unauthorised manner. Such actions should undeniably be penalised. The review of literature has provided evidence that there is a great need to focus on the ethos of neuroscience, especially as cases of misuse of its tools have already been identified. Nonetheless, the rapid progress of technology provides great opportunities for specialists from around the world to uncover the secrets of the human brain. Such activities, however, should only be undertaken having obtained 
the consent of the subjects and by making sure that they are fully aware of the testing techniques and ways of processing data.

Although neuroscience tools should be approached with caution, on no account should they be feared. Indeed, they can be of great help if used properly, as they may contribute to the development of many branches of science, such as medicine, economics and marketing.

\section{References}

1. Ahlert, D., Kenning, P., \& Plassmann, H. (2006). A window to the consumer's mind: application of functional brain imaging techniques to advertising research. International Advertising and Communication, pp. 163-178.

2. Ait Hammou, K., Galib, M.H., \& Melloul, J. (2013). The Contributions of Neuromarketing in Marketing Research. Journal of Management Research, 5(4), 20-32.

3. Andreassi, J.L. (2007). Psychophysiology. Human behavior \& physiological response (5th ed.). London: Lawrence Erlbaum Associates.

4. Ariely, D., \& Berns, G.S. (2010). Neuromarketing: the hope and hype of neuroimaging in business. Nature Reviews Neuroscience, 11(4), 284-292.

5. Ashby, F.G. (2011). Statistical analysis of fMRI data (2nd ed.). Cambridge, Massachusetts: MIT Press.

6. Banich, M., \& Compton, R. (2010). Cognitive Neuroscience (3, Ed.). Retrieved from https://scholarship.haverford.edu/psychology_facpubs/36.

7. Barker, A.T., Jalinous, R., \& Freeston, I.L. (1985). Non-invasive magnetic stimulation of human motor cortex. The Lancet, 325(8437), 1106-1107.

8. Boas, D.A., Elwell, C.E., Ferrari, M., \& Taga, G. (2014). Twenty years of functional nearinfrared spectroscopy: Introduction for the special issue. NeuroImage, 85, 15.

9. Boire, R.G. (1999). On Cognitive Liberty. Journal of Cognitive Liberties, 1(1), 1-26.

10. Bolls, A., Lang, R.F., \& Potter, P.D. (1995). The Effects of Message Valence and Listener Arousal on Attention, Memory, and Facial Muscular Responses to Radio Advertisements. Communication Research, 28(5), 627-651.

11. Boto, E., Holmes, N., Leggett, J., Roberts, G., Shah, V., Meyer, S.S., Brookes, M.J. (2018). Moving magnetoencephalography towards real-world applications with a wearable system. Nature, 555(7698), 657-661.

12. Boucsein, W. (2012). Electrodermal Activity. US: Springer.

13. Bradley, M.M., Miccoli, L., Escrig, M.A., \& Lang, P.J. (2008). The pupil as a measure of emotional arousal and autonomic activation. Psychophysiology, 45(4), 602-607.

14. Bridger, D. (2015). Decoding the irrational consumer: how to commission, run and generate insights from neuromarketing research. London: Kogan Page. 
15. Britannica (2019). Personal identity | Britannica. Retrieved December 14, 2019, from www.britannica.com website: https:/www.britannica.com/topic/personalidentity\#ref1111919.

16. Brunoni, A.R., Moffa, A.H., Fregni, F., Palm, U., Padberg, F., Blumberger, D.M., Loo, C.K. (2016). Transcranial direct current stimulation for acute major depressive episodes: metaanalysis of individual patient data. The British Journal of Psychiatry British Journal of Psychiatry, 208(6), 522-531.

17. Camerer, C.F., Loewenstein, G., \& Prelec, D. (2004). Neuroeconomics: Why Economics Needs Brains. The Scandinavian Journal of Economics, 106(3), 555-579.

18. Carlson, N.R. (2012). Physiology of Behavior (11th ed.). Boston, Massachusetts: Pearson.

19. Ciorcari, J. (2012). Bioelectrical signals: The electroencephalogram. In: A. Wood (Ed.), Physiology, biophysics and biomedical engineering. CRC Press.

20. Coenen, A., Fine, E., \& Zayachkivska, O. (2014). Adolf Beck: A Forgotten Pioneer in Electroencephalography. Journal of the History of the Neurosciences, 23(3), 276-286.

21. Cohen, D. (1968). Magnetoencephalography: Evidence of magnetic fields produced by alpha-rhythm currents. Science, 161(3843), 784-786.

22. Decker, M., \& Fleischer, T. (2008). Contacting the brain - Aspects of a technology assessment of neural implants. Biotechnology Journal, 3(12), 1502-1510.

23. Dedoncker, J., Brunoni, A.R., Baeken, C., \& Vanderhasselt, M.A. (2016). A Systematic Review and Meta-Analysis of the Effects of Transcranial Direct Current Stimulation (tDCS) Over the Dorsolateral Prefrontal Cortex in Healthy and Neuropsychiatric Samples: Influence of Stimulation Parameters. Brain Stimulation, 9(4), 501-517.

24. Dictionary, C.E. (2019). Neuromarketing definition and meaning | Collins English Dictionary. Retrieved December 14, 2019, from www.collins.com website: https://www.collinsdictionary.com/dictionary/english/neuromarketing.

25. Ekman, P., \& Friesen, W.V. (1971). Constants Across Cultures in the Face and Emotion. Journal Of Personality and Social Psychology, 71(2), 124-129.

26. Enserink, M., \& Chin, G. (2015). The end of privacy. Nature, 347(6221), 490-514.

27. Fetz, E.E. (1969). Operant conditioning of cortical unit activity. Science, 163(3870), $955-$ 958.

28. Frank, M.J., Samanta, J., Moustafa, A.A., \& Sherman, S.J. (2007). Hold your horses: impulsivity, deep brain stimulation, and medication in Parkinsonism. Science, 318(5854), 1309-1312.

29. Fugate, D.L. (2007). Neuromarketing: A layman's look at neuroscience and its potential application to marketing practice. Journal of Consumer Marketing, 24(7), 385-394.

30. Genco, S.J., Pohlmann, A.P., \& Steidl, P. (2013). Neuromarketing for dummies. Hoboken, New York: John Wiley \& Sons.

31. Gloor, P. (1969). Hans Berger and the discovery of the electroencephalogram. Electroencephalography and Clinical Neurophysiology, 28, 1-36. 
32. Harris, J.M., Ciorciari, J., \& Gountas, J. (2018). Consumer neuroscience for marketing researchers. Journal of Consumer Behaviour, 17(3), 239-252.

33. Hill, A.T., Fitzgerald, P.B., \& Hoy, K.E. (2016). Effects of Anodal Transcranial Direct Current Stimulation on Working Memory: A Systematic Review and Meta-Analysis of Findings from Healthy and Neuropsychiatric Populations. Brain Stimulation, 9(2), 197-208.

34. Horvath, J.C., Perez, J.M., Forrow, L., Fregni, F., \& Pascual-Leone, A. (2011). Transcranial magnetic stimulation: a historical evaluation and future prognosis of therapeutically relevant ethical concerns. Journal of Medical Ethics, 37(3), 137-143.

35. Houeto, J.L., Mesnage, V., Mallet, L., Pillon, B., Gargiulo, M., Tezenas du Moncel, S., Agid, Y. (2002). Behavioural disorders, Parkinson's disease and subthalamic stimulation. Journal of Neurology Neurosurgery and Psychiatry, 72(6), 701-707.

36. Hubert, M., \& Kenning, P. (2008). A current overview of consumer neuroscience. Journal of Consumer Behaviour, 7(4-5), 272-292.

37. Huettel, S.A., Song, A.W., \& McCarthy, G. (2008). Functional Magnetic Resonance Imaging (2nd ed.). Sunderland, Massachusetts: Sinauer Associates.

38. Ienca, M., \& Andorno, R. (2017). Towards new human rights in the age of neuroscience and neurotechnology. Life Sciences, Society and Policy, 13(1), 1-27.

39. Illes, J. (2003). Neuroethics in a new era of neuroimaging. AJNR. American Journal of Neuroradiology, 24(9), 1739-1741.

40. Isabella, G., Mazzon, J.A., \& Dimoka, A. (2015). Culture Differences, Difficulties, and Challenges of the Neurophysiological Methods in Marketing Research. Journal of International Consumer Marketing, 27(5), 346-363.

41. Katsoulaki, M., Kastrinis, A., \& Tsekoura, M. (2017). The effects of anodal transcranial direct current stimulation on working memory. Advances in Experimental Medicine and Biology, 987, 283-289.

42. Kenning, P.H., \& Plassmann, H. (2005). NeuroEconomics: An overview from an economic perspective. Brain Research Bulletin, 67(5), 343-354.

43. Khushaba, R.N., Kodagoda, S., Takruri, M., \& Dissanayake, G. (2012). Toward improved control of prosthetic fingers using surface electromyogram (EMG) signals. Expert Systems with Applications, 39(12), 10731-10738.

44. Kim, J. (Jamie), \& Fesenmaier, D.R. (2015). Measuring Emotions in Real Time. Journal of Travel Research, 54(4), 419-429.

45. Krucoff, M.O., Rahimpour, S., Slutzky, M.W., Edgerton, V.R., \& Turner, D.A. (2016). Enhancing nervous system recovery through neurobiologics, neural interface training, and neurorehabilitation. Frontiers in Neuroscience, 10(584), 39-52.

46. Lajante, M., \& Ladhari, R. (2019). The promise and perils of the peripheral psychophysiology of emotion in retailing and consumer services. Journal of Retailing and Consumer Services, 50, 305-313. 
47. Lavazza, A. (2018). Freedom of Thought and Mental Integrity: The Moral Requirements for Any Neural Prosthesis. Frontiers in Neuroscience, 12(82), 1-10.

48. Lee, N., Broderick, A.J., \& Chamberlain, L. (2007). What is "neuromarketing"? A discussion and agenda for future research. International Journal of Psychophysiology, 63(2), 199-204.

49. Levy, D.J., \& Glimcher, P.W. (2012). The root of all value: A neural common currency for choice. Current Opinion in Neurobiology, 22(6), 1027-1038.

50. Li, S., Scott, N., \& Walters, G. (2014). Current and potential methods for measuring emotion in tourism experiences: a review. Current Issues in Tourism, 18(9), 805-827.

51. Logothetis, N.K., Pauls, J., Augath, M., Trinath, T., \& Oeltermann, A. (2001). Neurophysiological Investigation of the Basis of the fMRI Signal. Nature, 412(6843), $150-157$.

52. Lone, F. (2009). How the Brain Reveals Why We Buy. Retrieved December 14, 2019, from Scientific American website: https://www.scientificamerican.com/article/neuromarketingbrain/.

53. Macdonald, M. (2011). Some ethical issues in brain imaging. CORTEX, 47, 1272-1274.

54. Mackenzie, R. (2011). Who Should Hold the Remote for the New Me? Cognitive, Affective, and Behavioral Side Effects of DBS and Authentic Choices Over Future Personalities. AJOB Neuroscience, 2(1), 18-20.

55. Mattson, J., \& Simon, M. (1996). The pioneers of NMR and magnetic resonance in medicine: the story of MRI. Jericho, New York: Dean Books.

56. Moore, A.D. (2010). Privacy rights: moral and legal foundations. University Park, Pennsylvania: The Pennsylvania State University Press.

57. Morin, C. (2011). Neuromarketing: The New Science of Consumer Behavior. Society, 48(2), 131-135.

58. Mucha, T. (2005). This is your brain on advertising. Retrieved December 9, 2019, from Business 2.0 website: https://archive.fortune.com/magazines/business2/business2_archive/ 2005/08/01/8269671/index.htm.

59. Mutz, J., Vipulananthan, V., Carter, B., Hurlemann, R., Fu, C.H.Y., \& Young, A.H. (2019). Comparative efficacy and acceptability of non-surgical brain stimulation for the acute treatment of major depressive episodes in adults: systematic review and network metaanalysis. BMJ Clinical Research, 364(1079), 1-13.

60. Ogawa, S., Lee, T.M., Kay, A.R., \& Tank, D. W. (1990). Brain magnetic resonance imaging with contrast dependent on blood oxygenation. Proceedings of the National Academy of Sciences, 87(24), 9868-9872.

61. Oğuz Tanzer, I. (2006). Numerical Modeling in Electro- and Magnetoencephalography, Doctoral Dissertation. Helsinki: Helsinki University of Technology. 
62. Ouazzani Touhami, Z., Benlafkih, L., Jiddane, M., Cherrah, Y., El Malki, H.O., \& Benomar, A. (2011). Neuromarketing: Where marketing and neuroscience meet. African Journal of Business Management, 5(5), 1528-1532.

63. Parent, A. (2004). Giovanni Aldini: From Animal Electricity to Human Brain Stimulation. The Canadian Journal of Neurological Sciences, 31(4), 576-584.

64. Perrachione, T.K., \& Perrachione, J.R. (2008). Brains and brands: developing mutually informative research in neuroscience and marketing. Journal of Consumer Behaviour, 7(4-5), 303-318.

65. Plakhin, A., Semenets, I., Ogorodnikova, E., \& Khudanina, M. (2018). New directions in the development of neuromarketing and behavioral economics. MATEC Web of Conferences, 184, 1-6. EDP Sciences.

66. Plassmann, H., Ambler, T., Braeutigam, S., \& Kenning, P. (2007). What can advertisers learn from neuroscience? International Journal of Advertising, 26(2), 151-175.

67. Pop, N.A., Dabija, D.-C., \& Iorga, A. (2014). Ethical Responsibility of Neuromarketing Companies in Harnessing the Market Research - a Global Exploratory Approach. Amfiteatru Economic, 16(35), 26-40.

68. Pradeep, A.K. (2010). The Buying Brain: Secrets for Selling to the Subconscious Mind. Hoboken, New Jersey: John Wiley \& Sons, Inc.

69. Reynolds, J. (2006). Measurement and Analysis for Marketing. Journal of Targeting, 14(3), 189-190.

70. Sanei, S., \& Chambers, J. (2007). EEG signal processing. Chichester, West Sussex: John Wiley and Sons Ltd.

71. Schacter, D.L. (1987). Implicit Memory: History and Current Status. Journal of Experimental Psycholog, 13(3), 501-518.

72. Schiffman, L.G., Kanuk, L.L., \& Wisenblit, J. (2010). Consumer Behavior (10th ed.). Upper Saddle River, New Jersey: Pearson Prentice Hall.

73. Sententia, W. (2006). Neuroethical Considerations: Cognitive Liberty and Converging Technologies for Improving Human Cognition. Annals of the New York Academy of Sciences, 1013(1), 221-228.

74. Shiv, B., Alba, J.W., Bettman, J.R., Mellers, B., \& Mcgraw, A.P. (2005). Decision Neuroscience. Marketing Letters, 16(4), 375-386.

75. Šola, M.H. (2013). Neuromarketing - Science and Practice. Financije i Pravo, 1(1), 25-34.

76. Spence, C., \& Piqueras-Fiszman, B. (2014). The perfect meal: the multisensory science of food and dining. Chichester, West Sussex: John Wiley and Sons Ltd.

77. Świerczyńska-Kaczor, U. (2015). Neuroscience in Consumer Marketing Research: an Analysis Drawn from the Examples of Food Products. Acta Scientiarum Polonorum. Oeconomia, 14(nr 2), 163-172.

78. Ter-Pogossian, M.M., Phelps, M.E., Hoffman, E.J., \& Mullani, N.A. (1975). A PositronEmission Transaxial Tomograph for Nuclear imaging (PETT). Radiology, 114(1), 89-98. 
79. Thoits, P.A. (1989). The Sociology of Emotions. Annual Review of Sociology, 15(1), 317342.

80. Ullman, M.T. (2004). Contributions of memory circuits to language: The declarative/ procedural model. Cognition, 92(1-2), 231-270.

81. Van Doorn, G., \& Miloyan, B. (2018). The Pepsi Paradox: A review. Food Quality and Preference, 65, 194-197.

82. Wang, Y.J., \& Minor, M.S. (2008). Validity, reliability, and applicability of psychophysiological techniques in marketing research. Psychology and Marketing, 25(2), 197-232.

83. Wilson, T.D., \& Dunn, E.W. (2004). Self-Knowledge: Its Limits, Value, and Potential for Improvement. Annu. Rev. Psychol, 55(1), 17.1-17.26.

84. Winkielman, P., Knutson, B., Paulus, M., \& Trujillo, J.L. (2007). Affective Influence on Judgments and Decisions: Moving Towards Core Mechanisms. Review of General Psychology, 11, 179-192.

85. Zurawicki, L. (2010). Neuromarketing Exploring the Brain of the Consumer. In: Neuromarketing: Exploring the Brain of the Consumer. Apringer, Heilderberg, Dordrecht, London, New York: Springer. 